\title{
Theoretical Verification of Wagner's Equation Considering Polarization Voltage Losses in SOFCs
}

\author{
T. Miyashita*
}

1-6-3, Mitsuya-kita, Yodogawa-ku, Osaka, 532-0032, Japan

\begin{abstract}
The necessity for experimental verification of leakage currents using Sm-doped ceria electrolytes (SDC) in solid-oxide fuel cells (SOFCs) has been indicated. This paper describes the theoretical limitations of Wagner's equation and details the analytical work that has been performed to support the experimental results. These limitations cannot be solved, even considering polarization voltage losses. Globally, there are several research groups working on SOFCs to solve the current-voltage relation with mixed ionic electronic solid conductors (MIECs). However, this problem must be solved considering the electric field (E) in MIECs. Thus, even though articles have already been published in similar areas, no approach has been taken within this body of work that considers the E in MIECs. In this report, a new calculation method considering E is expressed only from Wagner's equation, with continuity expressed using the Choudhury and Patterson style. The calculated results match the values from conventional models. The constant field approximation is verified using the conventional definition of E. However, the definition of $\mathrm{E}$ should be changed when there is a large voltage drop in the thin area of the electrolyte compared with the lattice constant. In this study, the electric field near the cathode is sufficiently large to cause dielectric breakdown, which has never been reported.
\end{abstract}

Keywords: SOFC, MIEC, ceria, Wagner's equation, Riess's model, polarization loss.

\section{INTRODUCTION}

Solid-oxide fuel cells (SOFCs) directly convert the chemical energy of fuel gases, such as hydrogen or methane, into electrical energy. In SOFCs, a solid-oxide film is used as the electrolyte. Oxygen ions serve as the main charge carriers in the electrolyte. In these cells, YSZ (yttria-stabilized zirconia) is typically used as the electrolyte material. If the operating temperature (873-1273 K) were lowered, the lifespan of the cells would be extended. Lowering the temperature enables the use of higher ion-conducting electrolyte materials, such as Sm-doped ceria electrolytes (SDC). However, the open current voltage (OCV) using an SDC cell is about $0.8 \mathrm{~V}$, which is lower than the Nernst voltage $\left(\mathrm{V}_{\mathrm{th}}=1.15 \mathrm{~V}\right)$. This low $\mathrm{OCV}$ value is considered to be due to the low value of the ionic transference number (tion). OCV is expressed as

$O C V=t_{\text {ion }} \times \frac{R T}{4 F} \ln \left(\frac{p O_{2}^{\prime}}{p O_{2}^{\prime \prime}}\right)=t_{\text {ion }} \times V_{\text {th }}$

$t_{\text {ion }}=\frac{R_{e}}{R_{i}+R_{e}}$

where $\mathrm{R}$ is the gas constant, $\mathrm{T}$ is the absolute temperature in Kelvin, $p O_{2}^{\prime}$ and $p O_{2}^{\prime \prime}$ are the oxygen partial pressures at the cathode and anode, respectively, and Ri and Re are the ionic resistance and the electronic resistance of the electrolyte, respectively. The energy conversion efficiency of SOFCs is determined by the ratio of the operating voltage to

*Address correspondence to this author at the 1-6-3, Mitsuya-kita, Yodogawa-ku, Osaka, 532-0032, Japan; Tel: 090-1204-1259;

Fax:+81-797-32-6171; E-mail: tom_miya@ballade.plala.or.jp the theoretical voltage. Consequently, the investigation of voltage loss in the OCV is very important. In general, tion is not constant in the electrolyte. Therefore, OCV can be explained by Wagner's equation [1], which is expressed as

$O C V=\frac{1}{4 F} \int_{\mu O_{2}^{\prime}}^{\mu O_{2}^{\prime \prime}} t_{i o n} d \mu O_{2}$

where $\mathrm{F}$ is Faraday's constant, and $\mu^{\prime} O_{2}$ and $\mu^{\prime \prime} O_{2}$ are the oxygen chemical potentials on the cathodic and anodic sides of the electrolyte, respectively. The oxygen chemical potential is given by

$$
\mu O_{2}=\mu O_{2}^{0}+R T \ln \left(\frac{p O_{2}}{p O_{2}^{0}}\right)
$$

where the standard oxygen chemical potential and the standard oxygen pressure are represented as $\mu O_{2}^{0}$ and $p \mathrm{O}_{2}^{0}$, respectively. Combining Equations 3 and 4 gives [2]

$O C V=\frac{R T}{4 F} \int_{p O_{2}^{\prime}}^{p O^{\prime \prime}} t_{i o n} d \ln p O_{2}$

Equation 5 is a classical equation that is still used in modern theoretical calculations [3]. The current-voltage relation to generalize Equation 5 was calculated from the constant field approximation [4]. With mixed conducting electrolytes, there are ionic (Ii) and electronic currents (Ie), even in the absence of an external current (Iext).

Experimental verification of leakage currents using SDC electrolytes (Ie) is necessary, both qualitatively [5] and quantitatively [6]. Two kinds of conclusions can be made when the experimental results are different from theoretical results: 
Case 1: The theory is perfect; however, there are technological problems [7].

Case 2: There is a voltage loss that cannot be explained by any available theories [8].

If there is confusion between Case 1 and Case 2, problems will arise in the use of mixed ionic electronic solid conductors (MIECs), not only in SOFCs but also in other every area of solid-state ionics. The problem has to be solved considering the electric field in MIECs [9]. Thus, even though papers have been published in similar areas, no approach has been taken that considers the electric field (E) in MIECs. In this report, a new calculation method considering $\mathrm{E}$ is expressed from Wagner's equation and expressed in the Choudhury and Patterson style [10], using a definition of $\mathrm{E}$ that will be discussed in detail. Furthermore, the polarization voltage losses are taken into account.

\section{NEW CALCULATION METHOD FOR THE CURRENT-VOLTAGE RELATION IN MIECS}

\subsection{Basic Theorem for Numerical Calculation}

To calculate the current-voltage relation in MIECs, we consider the following:

$I_{i}=r \times I_{e}$

$r<0$

where $r$ is the ratio of the ionic to the electronic current, which is constant throughout the electrolyte under steady-state conditions. Equation 6 was used by Choudhury and Patterson [10]

$$
\begin{aligned}
& I_{\text {ext }}=I_{i}+I_{e}=\left(1+\frac{1}{r}\right) \times I_{i} \\
& I_{i}=\frac{V_{\text {th }}-V_{\text {cell }}}{R_{i}} \\
& I_{e}=-\frac{V_{\text {cell }}}{R_{e}}
\end{aligned}
$$

where Vcell and Iext are the cell voltage and output current, respectively. From Equations 6, 8, 9 and 10,

$$
\begin{aligned}
& \frac{V_{\text {th }}-V_{\text {cell }}}{R_{i}}=-\frac{r \times V_{\text {cell }}}{R_{e}} \\
& V_{\text {cell }}=\frac{R_{e}}{r \times R_{i}-R_{e}} V_{\text {th }} \\
& V_{\text {cell }}=\frac{R_{e}}{r \times R_{i}-R_{e}} V_{\text {th }}=\frac{t_{\text {ion }}}{(r+1) \times t_{\text {ion }}-r} V_{t h}=f(r) \times V_{\text {th }}
\end{aligned}
$$

where $\mathrm{f}(\mathrm{r})$ is solely a function of $r$. If tion is not constant for the electrolytes, then $\mathrm{f}(\mathrm{r})$ is not constant.

$$
0 \leq f(r)<1
$$

Therefore, the generalized version of Wagner's equation is as follows:
$V_{c e l l}=\frac{R T}{4 F} \int_{p O_{2}^{\prime}}^{p O_{2}^{\prime \prime}} f(r) d \ln p O_{2}$

When $r$ is $-1, \mathrm{~V}$ cell is equal to the $\mathrm{OCV}$, and Equation 15 becomes equivalent to Equation 5. For doped Ceria electrolytes, tion is expressed as [3]

$$
t_{\text {ion }}=\frac{1}{1+\left(\frac{p O_{2}}{p O_{2}^{*}}\right)^{-\frac{1}{4}}}
$$

where $\mathrm{pO}_{2}^{*}$ corresponds to an oxygen partial pressure at which the ionic transference number is 0.5 . The following principles allow us to mathematically solve Equation 15 from Equation 16.

Principle 1: Having allowed the use of several arrangements, final mathematical solutions were already obtained by Choudhury and Patterson in the 1970s [10].

Principle 2: A numerical method that uses a spatial discretization approach with many mesh elements is useful for calculating the precise electric field in the electrolyte without using any assumptions

The thickness of each mesh is

$l_{\text {mesh }}=l_{\text {average }}\left(\frac{1-f_{\text {mesh }}(r)}{1-f_{\text {average }}(r)}\right)$

where faverage(r) is equal to $\mathrm{f}(\mathrm{r})$ in Equation 13, laverage is the average thickness of every mesh, and fmesh(r) and lmesh represent $f(r)$ and the actual thickness of each mesh, respectively. Equation 17 demonstrates that lmesh should be very small when fmesh(r) is near 1 . A mathematical proof of Equation 17 is given in the Appendix. Equation 17 is important for two reasons: (1) it is a basic theorem that enables numerical calculations to be performed easily (described in section 2.2), and (2) it is necessary for the mathematical definition of the electrical field (described in section 4).

\subsection{Calculation Procedure}

\subsubsection{Basic Calculation Procedure}

The calculation procedure is separated into three steps:

Procedure 1: Current-voltage relationship in MIEC

Procedure 2: Electrical potential in MIEC

Procedure 3: Electrical field in MIEC

In this section, Procedure 1 and Procedure 2 are explained. Procedure 3 is explained in section 4

\subsubsection{Basic Data for Calculation}

Calculations were performed using the Microsoft Excel software package, and only five basic data points were required. To greatly simplify the calculation, the ionic resistance of the electrolyte was assigned the value of $1 \mathrm{ohm}$. The correction for different ionic resistances is very simple.

Datum 1: Absolute temperature: T (K)

Datum 2: Cathode oxygen pressure: $p O_{2}^{\prime}$ (atm)

Datum 3: Anode oxygen pressure: $p O_{2}^{\prime \prime}$ (atm) 
Datum 4: Oxygen partial pressure at which the ionic transference number is 0.5: $p O_{2}^{*}$ (atm)

Datum 5: Ionic conductivity $(\mathrm{S} / \mathrm{cm})$

Data 4 and 5 are the physical measurements]. Vth can be calculated from Data 1,2 and 3.

\subsubsection{Calculation Procedure without Polarization Voltage Losses}

2.2.3.1. Procedure 1: Current-Voltage Relationship in a MIEC

The value $r$ is the ratio of the ionic to the electronic current, which is constant throughout the electrolyte under steady-state conditions. One calculation seat is needed for each $r$. An example sat using 30 meshes when $r$ is -2 is shown in Table 1. The precision of the calculation improved when the number of mesh elements was increased.

Step 1: Input r (e.g., $\mathrm{r}=-2)$.

Step 2: $\log \left(p O_{2_{-} m e s h}\right)=\frac{\log \left(p O_{2}^{\prime \prime}\right)-\log \left(p O_{2}^{\prime}\right)}{N} \times m$

is calculated in column 1 .

here, $\mathrm{pO}_{2 \text { _mesh }}$ and $\mathrm{m}$ are the partial oxygen pressure in each mesh and the mesh number, respectively.

Step 3: $\mathrm{pO}_{2 \_ \text {mesh }}$ is calculated from $\log \left(\mathrm{pO}_{2_{\_} \text {mesh }}\right)$ in column 2 .

Step 4: $\quad t_{\text {ion_mesh }}=\frac{1}{1+\left(\frac{p O_{2 \_m e s h}}{p O_{2}^{*}}\right)^{-\frac{1}{4}}}$ is calculated using Equation 16 in column 3.

here, $t_{\text {ion_mesh }}$ is the ionic transference number of each mesh.

Step 5: $f_{\text {mesh }}(r)=\frac{t_{\text {ion_mesh }}}{(r+1) \times t_{\text {ion_mesh }}-r}$ is calculated using Equation 13 in column 4.

Step 6: $f_{\text {average }}(r)=\frac{\sum_{1}^{N} f_{\text {mesh }}(r)}{N}$

Here Vcell, Ii and Ie can be calculated from faverage(r) using Equations 6, 9 and 10. Thus, by inputting many different values of $r$, the current-voltage relation for the MIEC can be obtained.

\subsubsection{Procedure 2: Electrical Potential in a MIEC}

To calculate the electric potential in the electrolyte, the following is performed:

Step 7: $\quad l_{\text {mesh }}=l_{\text {average }}\left(\frac{1-f_{\text {mesh }}(r)}{1-f_{\text {average }}(r)}\right)$ is calculated using faverage(r) and Equation 17 in column 5.

Step 8: The distance from the cathode $\left(\sum_{1}^{m} V_{m e s h}\right)$ is calculated in column 6 .
Step 9: $V_{\text {mesh }}=f_{\text {mesh }}(r) \times \frac{V t h}{N}$ is calculated in column 7 .

Step 10: The electric potential of the electrolyte is calculated as $\left(V_{\text {cell }}-\sum_{1}^{m-1} V_{\text {mesh }}\right)$ in column 8 .

\subsubsection{Calculation Procedure with Polarization Voltage Losses}

In general, Equation 1 is not fully correct, as there are polarization voltage losses that need to be considered. Considering polarization voltage losses,

$\mathrm{V}$ cell $=\mathrm{V}$ th - Rili - polarization voltage losses

There are two types of polarization voltage losses cathode polarization voltage loss and anode polarization voltage loss. The easiest method to calculate polarization voltage losses is to use a linear assumption:

Cathode polarization voltage loss $\left(\mathrm{V}_{\mathrm{c}}\right)=$ Rcathode $\times \mathrm{Ii}$

Anode polarization voltage loss $(\mathrm{Va})=$ Ranode $\times \mathrm{Ii}$

where Rcathode and Ranode are the ionic polarization resistances on the cathodic and anodic sides of the electrolyte, respectively. The main problems concerning polarization voltage loss are the decreasing cathode oxygen pressure and increasing anode oxygen pressure in the electrolyte.

$$
\begin{aligned}
& p O_{2_{\text {_cathode }}}=\frac{p O_{2}^{\prime}}{e^{V c \times \frac{4 F}{R T}}} \\
& p O_{2_{\text {_anode }}}=e^{\operatorname{Va\times \frac {4F}{RT}}} \times p O_{2}^{\prime \prime}
\end{aligned}
$$

with $\mathrm{pO}_{2 \text { _cathode }}$ and $\mathrm{pO}_{2 \text { _anode }}$ being the real partial oxygen pressures at the cathode and the anode in the electrolyte, respectively. Thus, the Nernst voltage considering polarization voltage losses (Vth_effective) is

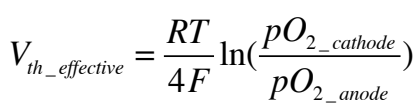

Using Equations 21, 22 and 23, an ionic current considering polarization voltage loss (Ii_effective) can be obtained using the method given in section 2.2.3.1. However, Ii_effective is different from Ii in Equation 19. Using the solver component in Microsoft Excel, when $\left(I_{i_{-} \text {effective }}-I_{i}\right)^{2}$ is near zero, the value of Ii changes. Upon inputting different values of $r$, the current-voltage relation considering polarization voltage losses in a MIEC is obtained. This method was carried out using complex formations to calculate polarization voltage losses.

\section{CALCULATION RESULTS}

\subsection{Calculation Situation}

Calculations were performed using 500 mesh elements in the Microsoft Excel software package. The temperature was $873 \mathrm{~K}$. Pure oxygen gas ( $1 \mathrm{~atm})$ was fed to the cathode, and hydrogen gas with $3 \%$ steam was supplied as the fuel gas to 
Table 1. The Calculated Results when $\mathbf{r}$ is -2

\begin{tabular}{|c|c|c|c|c|c|c|c|c|}
\hline Column & 1 & 2 & 3 & 4 & 5 & 6 & 7 & 8 \\
\hline $\begin{array}{l}\text { Mesh. } \\
\text { No. }\end{array}$ & $\begin{array}{c}\log \left(\mathrm{O}_{2}\right) \\
\log (\mathrm{atm})\end{array}$ & $\begin{array}{c}\mathrm{PO}_{2 \_} \text {mesh } \\
\text { (atm) }\end{array}$ & tion_mesh & $f(r)$ & $\begin{array}{l}\text { Lmesh } \\
(\%)\end{array}$ & $\begin{array}{l}\text { Distance } \\
\text { (\%) }\end{array}$ & $\begin{array}{l}\text { Vmesh } \\
\text { (Volt) }\end{array}$ & $\begin{array}{c}\text { Voltage } \\
\text { (Volt) }\end{array}$ \\
\hline 1 & -0.90 & $1.3 \mathrm{E}-01$ & 0.999999 & 0.999989 & $1.5 \mathrm{E}-04$ & $1.5 \mathrm{E}-04$ & 0.039 & 0.876 \\
\hline 2 & -1.81 & $1.6 \mathrm{E}-02$ & 0.999998 & 0.999981 & $2.5 \mathrm{E}-04$ & $4.0 \mathrm{E}-04$ & 0.039 & 0.837 \\
\hline 3 & -2.71 & $2.0 \mathrm{E}-03$ & 0.999997 & 0.999968 & 4.2E-04 & $8.1 \mathrm{E}-04$ & 0.039 & 0.798 \\
\hline 4 & -3.61 & $2.5 \mathrm{E}-04$ & 0.999995 & 0.999947 & $7.0 \mathrm{E}-04$ & $1.5 \mathrm{E}-03$ & 0.039 & 0.759 \\
\hline 5 & -4.51 & $3.1 \mathrm{E}-05$ & 0.999991 & 0.999910 & $1.2 \mathrm{E}-03$ & $2.7 \mathrm{E}-03$ & 0.039 & 0.720 \\
\hline 6 & -5.42 & $3.8 \mathrm{E}-06$ & 0.999985 & 0.999849 & $2.0 \mathrm{E}-03$ & 4.7E-03 & 0.039 & 0.681 \\
\hline 7 & -6.32 & $4.8 \mathrm{E}-07$ & 0.999975 & 0.999746 & $3.3 \mathrm{E}-03$ & $8.0 \mathrm{E}-03$ & 0.039 & 0.642 \\
\hline 8 & -7.22 & $6.0 \mathrm{E}-08$ & 0.999957 & 0.999573 & $5.6 \mathrm{E}-03$ & $1.4 \mathrm{E}-02$ & 0.039 & 0.602 \\
\hline 9 & -8.12 & 7.5E-09 & 0.999928 & 0.999282 & $9.4 \mathrm{E}-03$ & $2.3 \mathrm{E}-02$ & 0.039 & 0.563 \\
\hline 10 & -9.03 & $9.4 \mathrm{E}-10$ & 0.999879 & 0.998794 & $1.6 \mathrm{E}-02$ & $3.9 \mathrm{E}-02$ & 0.039 & 0.524 \\
\hline 11 & -9.93 & $1.2 \mathrm{E}-10$ & 0.999797 & 0.997973 & 2.7E-02 & $6.6 \mathrm{E}-02$ & 0.039 & 0.485 \\
\hline 12 & -10.83 & $1.5 \mathrm{E}-11$ & 0.999659 & 0.996597 & 4.5E-02 & $1.1 \mathrm{E}-01$ & 0.039 & 0.446 \\
\hline 13 & -11.74 & $1.8 \mathrm{E}-12$ & 0.999426 & 0.994291 & $7.5 \mathrm{E}-02$ & $1.9 \mathrm{E}-01$ & 0.039 & 0.407 \\
\hline 14 & -12.64 & $2.3 \mathrm{E}-13$ & 0.999036 & 0.990439 & $1.3 \mathrm{E}-01$ & $3.1 \mathrm{E}-01$ & 0.039 & 0.368 \\
\hline 15 & -13.54 & $2.9 \mathrm{E}-14$ & 0.998379 & 0.984027 & $2.1 \mathrm{E}-01$ & $5.2 \mathrm{E}-01$ & 0.039 & 0.329 \\
\hline 16 & -14.44 & $3.6 \mathrm{E}-15$ & 0.997278 & 0.973432 & $3.5 \mathrm{E}-01$ & $8.7 \mathrm{E}-01$ & 0.038 & 0.291 \\
\hline 17 & -15.35 & $4.5 \mathrm{E}-16$ & 0.995432 & 0.956123 & $5.8 \mathrm{E}-01$ & $1.4 \mathrm{E}+00$ & 0.037 & 0.253 \\
\hline 18 & -16.25 & $5.6 \mathrm{E}-17$ & 0.992343 & 0.928367 & $9.4 \mathrm{E}-01$ & $2.4 \mathrm{E}+00$ & 0.036 & 0.215 \\
\hline 19 & -17.15 & $7.1 \mathrm{E}-18$ & 0.987192 & 0.885160 & $1.5 \mathrm{E}+00$ & $3.9 \mathrm{E}+00$ & 0.035 & 0.179 \\
\hline 20 & -18.05 & $8.8 \mathrm{E}-19$ & 0.978651 & 0.820921 & $2.4 \mathrm{E}+00$ & $6.3 \mathrm{E}+00$ & 0.032 & 0.144 \\
\hline 21 & -18.96 & $1.1 \mathrm{E}-19$ & 0.964619 & 0.731641 & $3.5 \mathrm{E}+00$ & $9.8 \mathrm{E}+00$ & 0.029 & 0.112 \\
\hline 22 & -19.86 & $1.4 \mathrm{E}-20$ & 0.941910 & 0.618533 & $5.0 \mathrm{E}+00$ & $1.5 \mathrm{E}+01$ & 0.024 & 0.084 \\
\hline 23 & -20.76 & $1.7 \mathrm{E}-21$ & 0.906046 & 0.490924 & $6.7 \mathrm{E}+00$ & $2.1 \mathrm{E}+01$ & 0.019 & 0.059 \\
\hline 24 & -21.66 & $2.2 \mathrm{E}-22$ & 0.851529 & 0.364487 & $8.4 \mathrm{E}+00$ & $3.0 \mathrm{E}+01$ & 0.014 & 0.040 \\
\hline 25 & -22.57 & $2.7 \mathrm{E}-23$ & 0.773295 & 0.254344 & $9.8 \mathrm{E}+00$ & $4.0 \mathrm{E}+01$ & 0.010 & 0.026 \\
\hline 26 & -23.47 & $3.4 \mathrm{E}-24$ & 0.669821 & 0.168652 & $1.1 \mathrm{E}+01$ & $5.1 \mathrm{E}+01$ & 0.007 & 0.016 \\
\hline 27 & -24.37 & 4.2E-25 & 0.546798 & 0.107662 & $1.2 \mathrm{E}+01$ & $6.2 \mathrm{E}+01$ & 0.004 & 0.009 \\
\hline 28 & -25.28 & $5.3 \mathrm{E}-26$ & 0.417780 & 0.066952 & $1.2 \mathrm{E}+01$ & $7.5 \mathrm{E}+01$ & 0.003 & 0.005 \\
\hline 29 & -26.18 & $6.6 \mathrm{E}-27$ & 0.299113 & 0.040930 & $1.3 \mathrm{E}+01$ & $8.7 \mathrm{E}+01$ & 0.002 & 0.003 \\
\hline \multirow[t]{3}{*}{30} & -27.08 & $8.3 \mathrm{E}-28$ & 0.202432 & 0.024753 & $1.3 \mathrm{E}+01$ & $1.0 \mathrm{E}+02$ & 0.001 & 0.001 \\
\hline & & & & faverage(r) & & & Vcell & \\
\hline & & & & 0.74644 & & & 0.876 & \\
\hline
\end{tabular}

the anode (partial oxygen pressure is $8.3 \times 10^{-28}$ atm). Vth was $1.174 \mathrm{~V}$, and $p O_{2}^{*}$ was $2 \times 10^{-25}$ atm [6]. The conductivity was $0.02 \mathrm{~S} / \mathrm{cm}$. Using $1-\mathrm{cm}^{2}$ electrodes, the thickness was $0.02 \mathrm{~cm}$ when Ri was $1 \mathrm{ohm}$.

\subsection{I-V Relations without Polarization Voltage Losses}

The calculations for the relationship between tion and $\log \left(\mathrm{pO}_{2}\right)$ are shown in Fig. (1). These results agree with previous reports [6]. The calculation results at various values of $r$ are shown in Table 2.

From Riess's model [4],

$$
I_{e}=\frac{V_{t h}-V_{c e l l}}{R_{e_{-} \text {cathode }}} \times \frac{e^{-\beta q\left(V_{t h}-V_{\text {cell }}\right)}-e^{-\beta q V_{t h}}}{1-e^{-\beta q\left(V_{t h}-V_{\text {cell }}\right)}}
$$

where $\beta, q$ and $\operatorname{Re}_{-}$cathode are the reciprocal of the multiplication of the Boltzmann constant and the absolute temperature, the elementary charge and the electronic 
resistance near the cathode, respectively. Re_cathode was 3.94 ohm at OCV conditions. This value is much less than the resistance of air (on the order of $1 \mathrm{Mohm}$ ) when $\mathrm{Ri}$ is $1 \mathrm{ohm}$. This has been explained by the high mobility of the electrons. The ionic current-voltage relation, electronic current-voltage relation, external current-voltage relation and external current-power output relation are shown in Figs. (2-5), respectively. The calculated electronic current matches the values predicted by Reiss' model. This means that the distribution of electronic charge in Riess's model is already considered in Equation 16. Consequently, the compatibility between Riess's model and the generalized version of Wagner's equation using the Choudhury and Patterson style is verified. These results were reported in detail by R. Singh and K.T. Jacob [11].

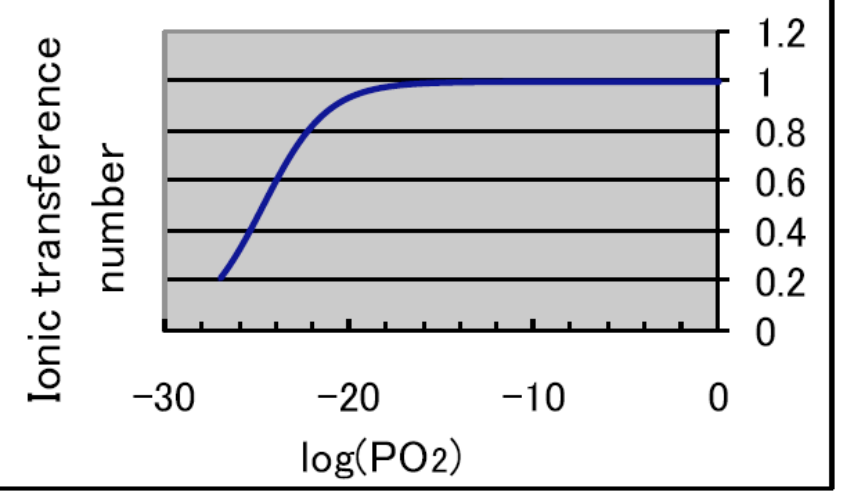

Fig. (1). Relationship between $\log \left(\mathrm{pO}_{2}\right)$ and tion.

These results agree with previously reported experimental results.

Table 2. Calculation Results at Different Values of $\mathbf{r}$. The I-V Relation was Obtained without any Mathematical Assumptions

\begin{tabular}{|r|c|c|c|c|c|}
\hline \multicolumn{1}{|r|}{$\mathbf{r}$} & $\begin{array}{c}\text { Vcell } \\
(\mathbf{V})\end{array}$ & $\begin{array}{c}\text { Ii } \\
(\mathbf{A})\end{array}$ & $\begin{array}{c}\text { Ie } \\
(\mathbf{A})\end{array}$ & $\begin{array}{c}\text { Iext } \\
(\mathbf{A})\end{array}$ & $\begin{array}{c}\text { Power } \\
(\mathbf{W})\end{array}$ \\
\hline \hline-0.033333 & 1.16485 & 0.00929 & -0.27868 & -0.26939 & -0.31380 \\
\hline-0.05 & 1.16060 & 0.01354 & -0.27074 & -0.25720 & -0.29851 \\
\hline-0.1 & 1.14913 & 0.02501 & -0.25008 & -0.22507 & -0.25863 \\
\hline-0.2 & 1.13039 & 0.04375 & -0.21875 & -0.17500 & -0.19782 \\
\hline-0.5 & 1.09217 & 0.08196 & -0.16392 & -0.08196 & -0.08952 \\
\hline-1 & 1.05386 & 0.12028 & -0.12028 & 0.00000 & 0.00000 \\
\hline-2 & 1.00969 & 0.16445 & -0.08222 & 0.08222 & 0.08302 \\
\hline-10 & 0.89558 & 0.27855 & -0.02786 & 0.25070 & 0.22452 \\
\hline-100 & 0.72386 & 0.45027 & -0.00450 & 0.44577 & 0.32268 \\
\hline-1000 & 0.55065 & 0.62348 & -0.00062 & 0.62286 & 0.34298 \\
\hline-10000 & 0.37769 & 0.79644 & -0.00008 & 0.79636 & 0.30078 \\
\hline-100000 & 0.20864 & 0.96549 & -0.00001 & 0.96548 & 0.20144 \\
\hline-1000000 & 0.06889 & 1.10524 & 0.00000 & 1.10524 & 0.07614 \\
\hline-10000000 & 0.01050 & 1.16363 & 0.00000 & 1.16363 & 0.01222 \\
\hline
\end{tabular}

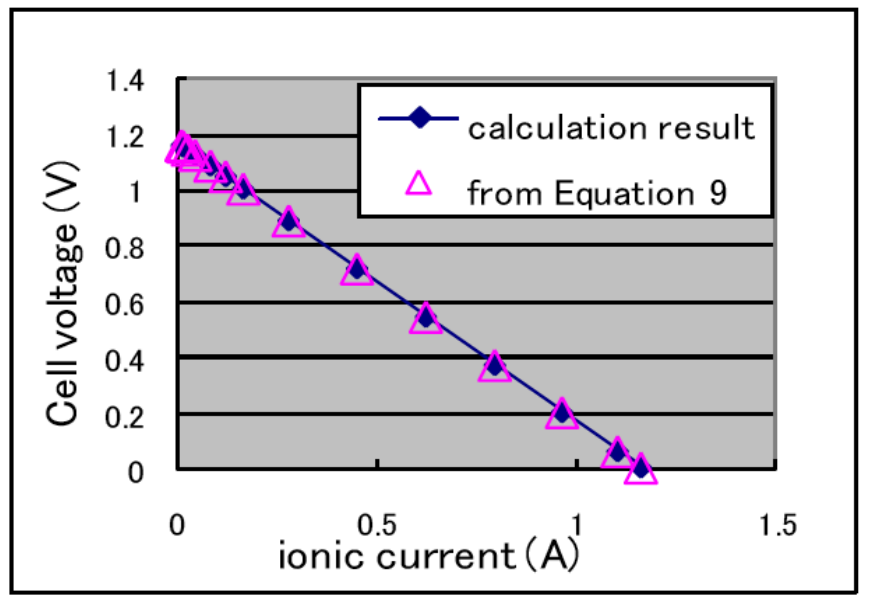

Fig. (2). Ionic current-voltage relation.

The calculation results agree with Eq. 9.

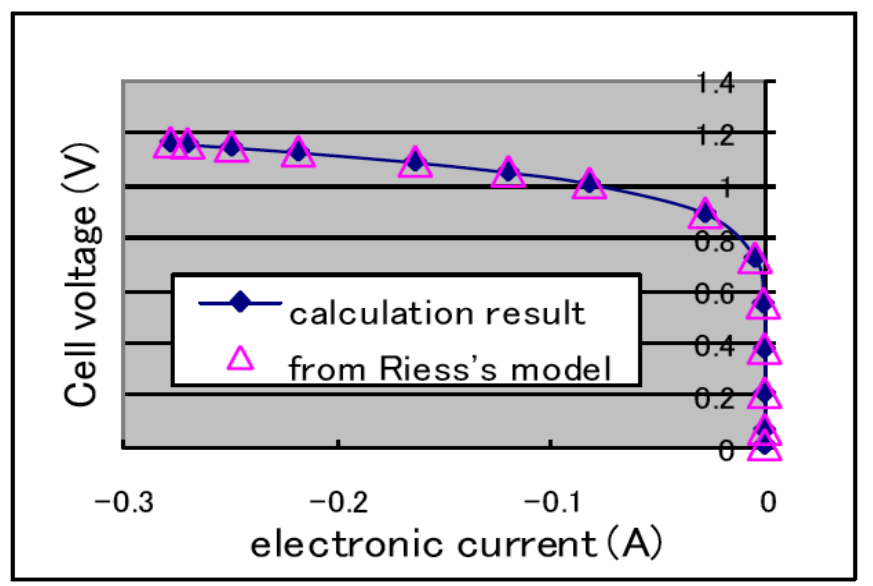

Fig. (3). Electronic current-voltage relation.

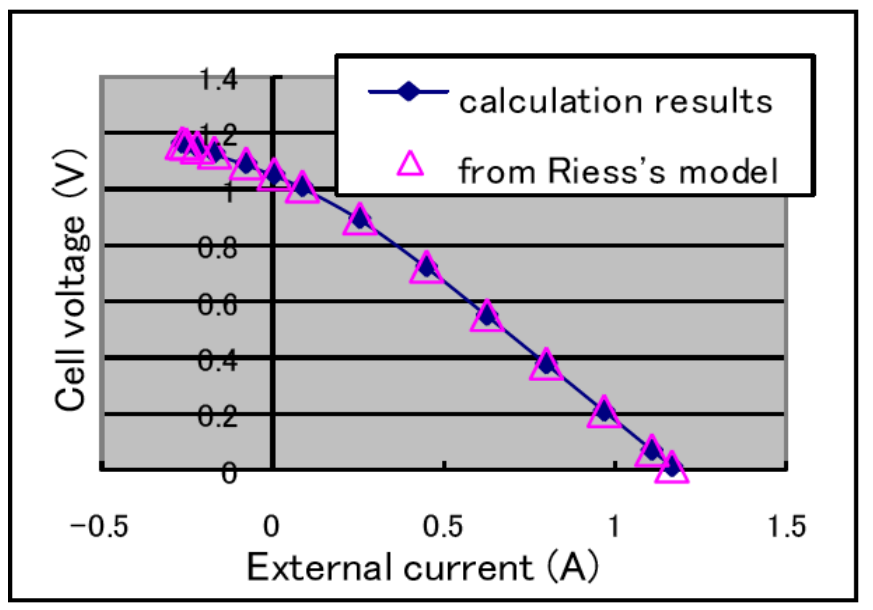

Fig. (4). External current-voltage relation.

The calculated electronic current, external current and power output match the values predicted by Reiss' model.

\subsection{Calculation Results with Polarization Voltage Losses}

\subsubsection{Calculation Situation Considering Polarization Voltage Losses}

Calculations were carried out using 30 mesh elements in Microsoft Excel. The parameters used in the calculations are 
identical to those described above in Section 3.1 for the calculations performed using 50 mesh elements. Rcathode was $0.3 \mathrm{ohm}$ and Ranode was $0.5 \mathrm{ohm}$.

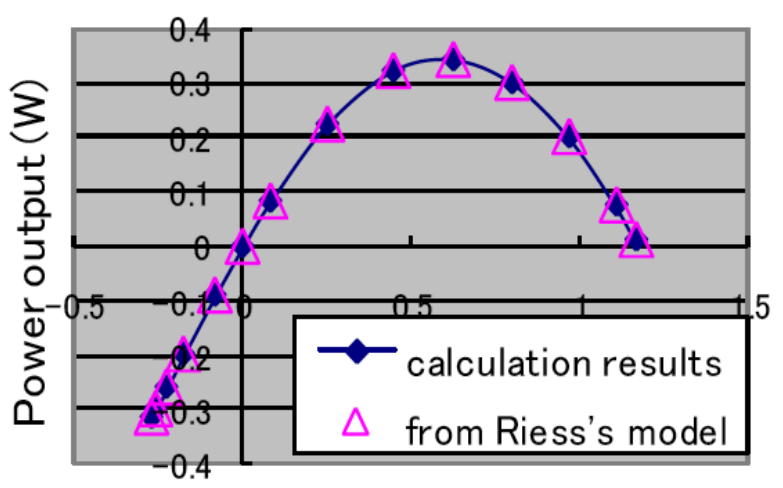

\section{External current $(A)$}

Fig. (5). External current-power output relation.

\subsubsection{Calculation Results with Polarization Voltage Losses}

Calculation results at various values of $r$ are shown in Table 3. The ionic current-voltage relation, electronic current-voltage relation, external current-voltage relation and external current-power output relation are shown in Figs (6-9), respectively. Compared with Figs. (2-5), these results confirm the validity of the calculation.
The external current-cathode voltage loss relation and the external current-anode voltage loss relation are shown in Figs. $(\mathbf{1 0}, \mathbf{1 1})$, respectively. Even if we use a linear assumption, the results are not in a line. The reason for this is that Iext is different from Ii. The difference between Iext and Ii becomes small and the curve becomes a line when Ii becomes large. Consequently, I-V relations considering polarization voltage losses can be calculated by this method.

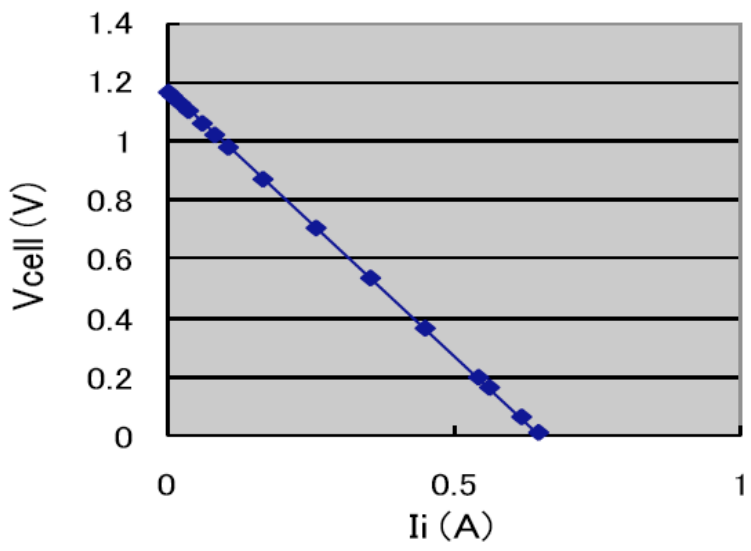

Fig. (6). Ionic current-voltage relation considering polarization voltage losses.

Using a linear assumption to calculate polarization voltage losses, the I-V relation should be a line.

Table 3. Calculation Results at Various Values of $r$ Considering Polarization Voltage Losses. The I-V Relation Considering Polarization Voltage Losses was Obtained by this Method

\begin{tabular}{|c|c|c|c|c|c|c|c|}
\hline $\mathbf{r}$ & $\begin{array}{l}\text { Vcell } \\
\text { (V) }\end{array}$ & $\begin{array}{c}\text { Ii } \\
\text { (A) }\end{array}$ & $\begin{array}{l}\text { Ie } \\
\text { (A) }\end{array}$ & $\begin{array}{c}\text { Iext } \\
\text { (V) }\end{array}$ & $\begin{array}{c}\text { Power } \\
\text { (W) }\end{array}$ & $\begin{array}{l}\text { Ve } \\
\text { (V) }\end{array}$ & $\begin{array}{l}\text { Va } \\
\text { (V) }\end{array}$ \\
\hline-0.0333 & $1.16 \mathrm{E}+00$ & $1.06 \mathrm{E}-02$ & $-3.17 \mathrm{E}-01$ & $-3.06 \mathrm{E}-01$ & $-3.54 \mathrm{E}-01$ & $3.17 \mathrm{E}-03$ & $5.28 \mathrm{E}-03$ \\
\hline-0.01 & $1.17 \mathrm{E}+00$ & $3.58 \mathrm{E}-03$ & $-3.58 \mathrm{E}-01$ & $-3.54 \mathrm{E}-01$ & $-4.13 \mathrm{E}-01$ & $1.07 \mathrm{E}-03$ & $1.79 \mathrm{E}-03$ \\
\hline-0.1 & $1.13 \mathrm{E}+00$ & $2.47 \mathrm{E}-02$ & $-2.47 \mathrm{E}-01$ & $-2.22 \mathrm{E}-01$ & $-2.51 \mathrm{E}-01$ & $7.41 \mathrm{E}-03$ & $1.24 \mathrm{E}-02$ \\
\hline-0.5 & $1.06 \mathrm{E}+00$ & $6.25 \mathrm{E}-02$ & $-1.25 \mathrm{E}-01$ & $-6.25 \mathrm{E}-02$ & $-6.64 \mathrm{E}-02$ & $1.88 \mathrm{E}-02$ & $3.13 \mathrm{E}-02$ \\
\hline-1 & $1.02 \mathrm{E}+00$ & $8.41 \mathrm{E}-02$ & $-8.41 \mathrm{E}-02$ & $0.00 \mathrm{E}+00$ & $0.00 \mathrm{E}+00$ & $2.52 \mathrm{E}-02$ & $4.20 \mathrm{E}-02$ \\
\hline-2 & $9.80 \mathrm{E}-01$ & $1.08 \mathrm{E}-01$ & $-5.39 \mathrm{E}-02$ & $5.39 \mathrm{E}-02$ & $5.28 \mathrm{E}-02$ & $3.23 \mathrm{E}-02$ & $5.39 \mathrm{E}-02$ \\
\hline-10000 & $3.64 \mathrm{E}-01$ & $4.50 \mathrm{E}-01$ & $-4.50 \mathrm{E}-05$ & $4.50 \mathrm{E}-01$ & $1.64 \mathrm{E}-01$ & $1.35 \mathrm{E}-01$ & $2.25 \mathrm{E}-01$ \\
\hline-100000 & $1.97 \mathrm{E}-01$ & $5.43 \mathrm{E}-01$ & $-5.43 \mathrm{E}-06$ & $5.43 \mathrm{E}-01$ & $1.07 \mathrm{E}-01$ & $1.63 \mathrm{E}-01$ & $2.71 \mathrm{E}-01$ \\
\hline-166667 & $1.62 \mathrm{E}-01$ & $5.62 \mathrm{E}-01$ & $-3.37 \mathrm{E}-06$ & $5.62 \mathrm{E}-01$ & $9.13 \mathrm{E}-02$ & $1.69 \mathrm{E}-01$ & $2.81 \mathrm{E}-01$ \\
\hline$-1 \mathrm{E}+06$ & $6.22 \mathrm{E}-02$ & $6.18 \mathrm{E}-01$ & $-6.18 \mathrm{E}-07$ & $6.18 \mathrm{E}-01$ & $3.84 \mathrm{E}-02$ & $1.85 \mathrm{E}-01$ & $3.09 \mathrm{E}-01$ \\
\hline$-1 E+07$ & $9.13 \mathrm{E}-03$ & $6.47 \mathrm{E}-01$ & $-6.47 \mathrm{E}-08$ & $6.47 \mathrm{E}-01$ & $5.91 \mathrm{E}-03$ & $1.94 \mathrm{E}-01$ & $3.24 \mathrm{E}-01$ \\
\hline
\end{tabular}




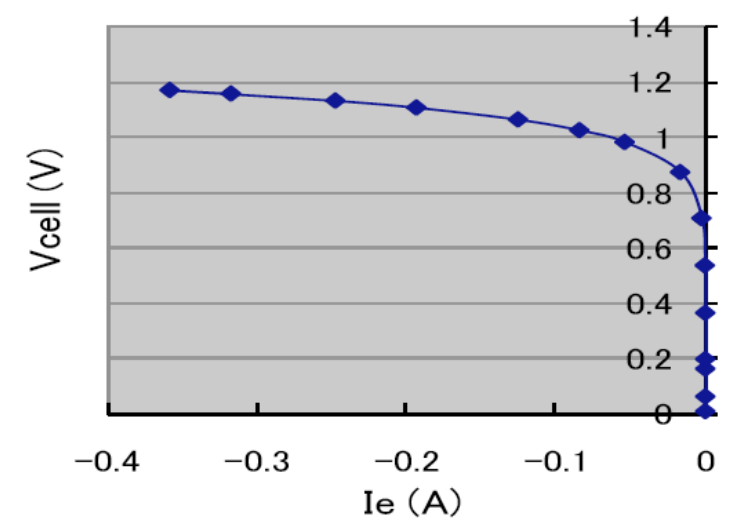

Fig. (7). Electronic current-voltage relation considering polarization voltage losses.

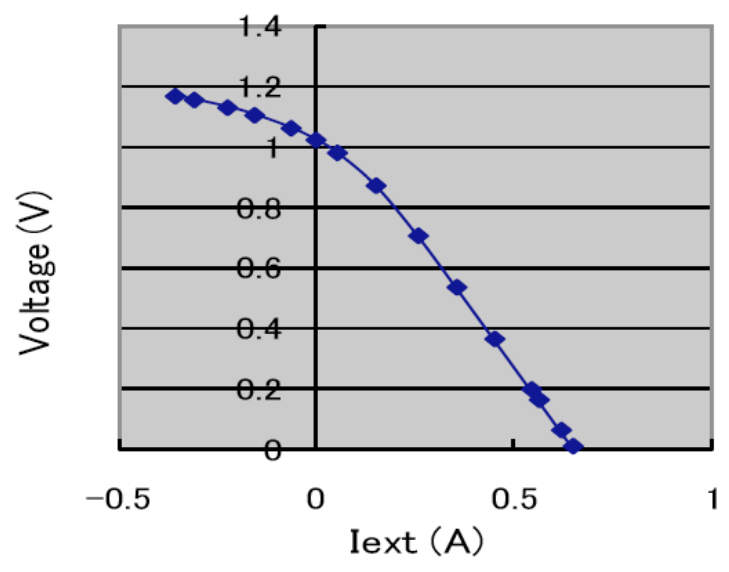

Fig. (8). External current-voltage relation considering polarization voltage losses.

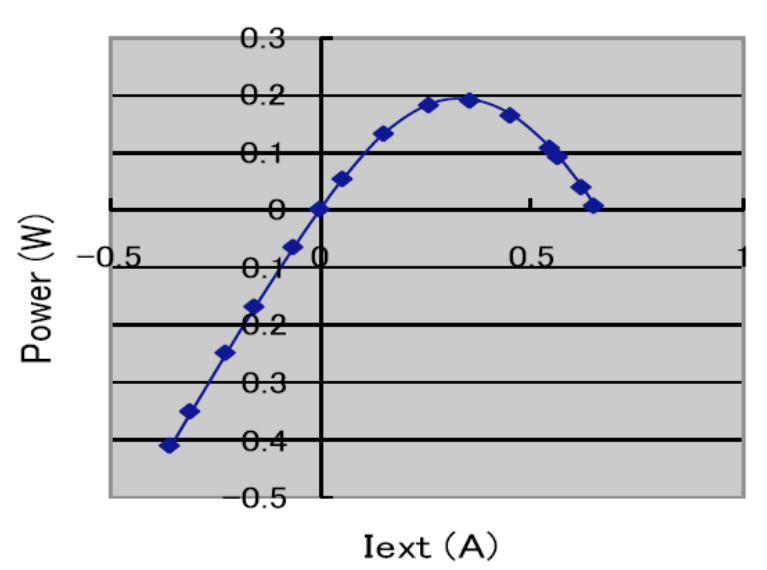

Fig. (9). External current-power output relation considering polarization voltage losses.

Compared with Figs. (3-5), the respective results of Figs. (7-9) confirm the validity of the calculation.

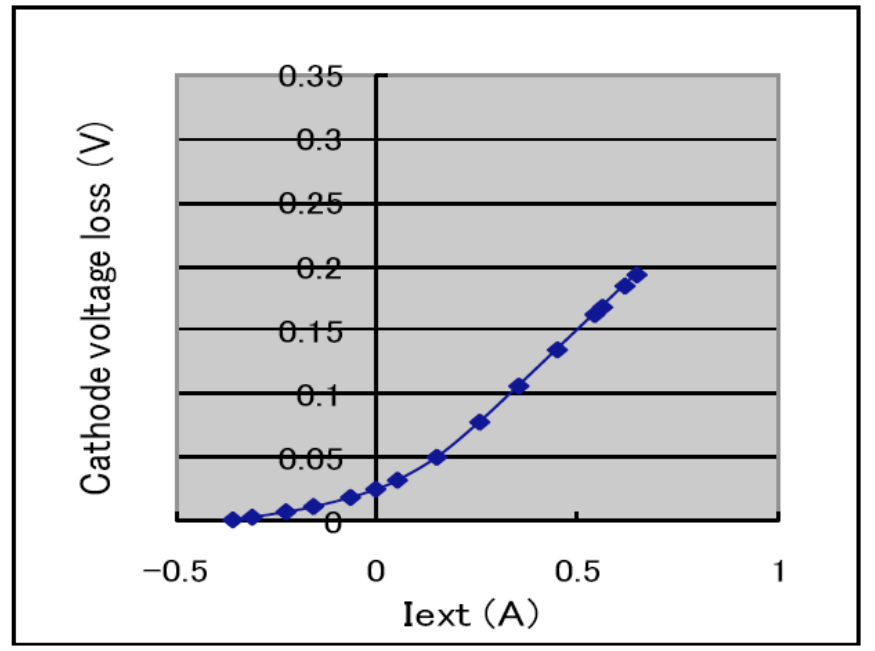

Fig. (10). External current-cathode voltage loss relation.

These results confirm the validity of the calculation.

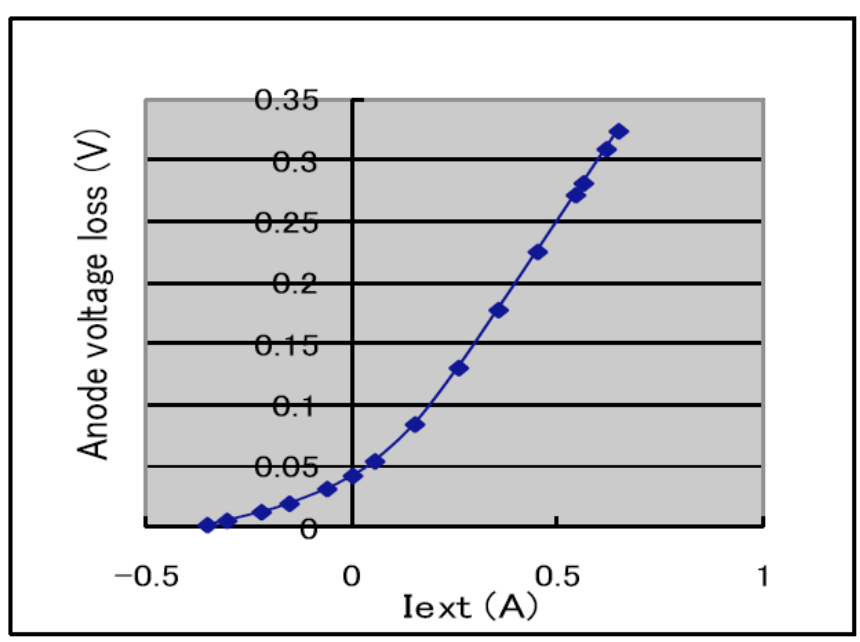

Fig. (11). External current-anode voltage loss relation.

These results confirm the validity of the calculation.

\section{DISCUSSION}

\subsection{The Conventional Calculation of the Electric Field}

The superiority of this numerical method for solving the generalized version of Wagner's equation using the Choudhury and Patterson style is in the simplicity of its mathematical definition of electrical field. There is no electric field in the ionic conductors without current because ionic carriers neutralize the electric field. This means that $\mathrm{dV} / \mathrm{dx}$ is not $\mathrm{E}$, and $\mathrm{E}$ is expressed as [12].

$E_{\text {ions }}=\frac{\frac{V_{\text {th }}}{N}-V_{\text {mesh }}}{l_{\text {mesh }}}=\frac{V_{\text {th }} \times\left(1-f_{\text {mesh }}(r)\right)}{L} \times\left(\frac{1-f_{\text {average }}(r)}{1-f_{\text {mesh }}(r)}\right)=\frac{V_{\text {th }}-V_{\text {cell }}}{L}$

so,

$E_{\text {ions }}=\frac{V_{\text {th }}-V_{\text {cell }}}{L}=\frac{\left(V_{\text {th }}-V_{\text {cell }}\right)}{R_{i} \times \sigma_{i} \times S}=\frac{I i}{\sigma_{i} \times S}$ 
where $\sigma_{i}$ and $\mathrm{S}$ are the ionic conductance and electrode area. In Equation 25, $\mathrm{E}$ has the same value in every mesh element. Equation 26 is the ohmic law. Thus, the constant field approximation is verified. This means that Riess's model is compatible with the generalized version of Wagner's equation using the Choudhury and Patterson style. Consequently, the constant field approximation (linear assumption) is not an approximation but the direct deduction from Wagner's equation.

\subsection{The Limitations of Wagner's Equation Considering $\mathbf{E}$}

The calculated relationship between the distance from the cathode and electrostatic potential under OCV conditions is shown in Fig. (12). The calculated relationship between the distance from the cathode and $\log (\mathrm{E})$ under OCV conditions is shown in Fig. (13). Under the OCV condition, a large voltage drop $(0.46 \mathrm{~V})$ was observed within $0.02 \%$ of the thickness of the electrolytes near the cathode. For $0.02-\mathrm{cm}$-thick electrolytes, this distance was $40 \mathrm{~nm}$. The lattice constant was $0.54 \mathrm{~nm}$, which means that there were only 74 lattice elements within the 40-nm distance.

For ions, next equation is right:

$E_{\text {ions }}=\frac{\frac{V_{\text {th }}}{N}-V_{\text {mesh }}}{l_{\text {mesh }}}=\frac{V_{\text {th }} \times\left(1-f_{\text {mesh }}(r)\right)}{L} \times\left(\frac{1-f_{\text {average }}(r)}{1-f_{\text {mesh }}(r)}\right)=\frac{V_{\text {th }}-V_{\text {cell }}}{L}$

Here $E_{\text {ions }}$ is electrical field for ions. But for electrons

$$
E_{\text {elevtrons }}=\frac{V_{\text {mesh }}}{l_{\text {mesh }}}=\frac{V_{\text {th }} \times f_{\text {mesh }}(r)}{L} \times\left(\frac{1-f_{\text {average }}(r)}{1-f_{\text {mesh }}(r)}\right)
$$

Here $E_{\text {electrons }}$ is electrical field for electrons. So the definitions of $\mathrm{E}$ are different between ions and electrons. In doped ceria electrolyte, the pass ways of ions and electrons are different, so there are no problems about the definitions different of $\mathrm{E}$.

Ionic transference number can be measured only when Eelectrons are small enough to cause dielectric break down.

The value of $\mathrm{E}$ increases with an increase in fmesh(r). Consequently, E cannot be constant. This means that the constant field approximation in Riess's model cannot be used in this case.

Furthermore, as is shown in Fig. (13), a serious problem was discovered in our calculation. Even for an electrolyte that was $0.02-\mathrm{cm}$-thick, E near the cathode was greater than $800 \mathrm{kV} / \mathrm{mm}$. This value is sufficiently large to cause dielectric breakdown, as Pyrex glass at 1-mm thickness undergoes dielectric breakdown at only $20 \mathrm{kV}$. However, a dielectric breakdown, which would manifest itself as pinholes or sharp current noises, has never been reported. As a valuable practical aspect, the entire system stability will be lost. From Equation 28, fmesh(r) is;

$f_{\text {mesh }}(r)=\frac{E \times L}{E \times L+\left(1-f_{\text {average }}(r)\right) \times V_{\text {th }}}$

From Equation 29, fmesh(r) is 0.99997 with E, faverage(r), $\mathrm{L}$ and $\mathrm{Vth}$ at $20 \mathrm{kV} / \mathrm{mm}, 0.898,0.02 \mathrm{~cm}$ and $1.174 \mathrm{~V}$, respectively. Thus, $p O_{2 \_m e s h}$ is $2.46 \times 10^{-7}$ atm. This

value is much smaller than the cathode oxygen gas pressure $1 \mathrm{~atm}$; thus, it is difficult to avoid a large electric field in the electrolyte. One solution may be considering cathode polarization voltage loss, which is described in the next section.

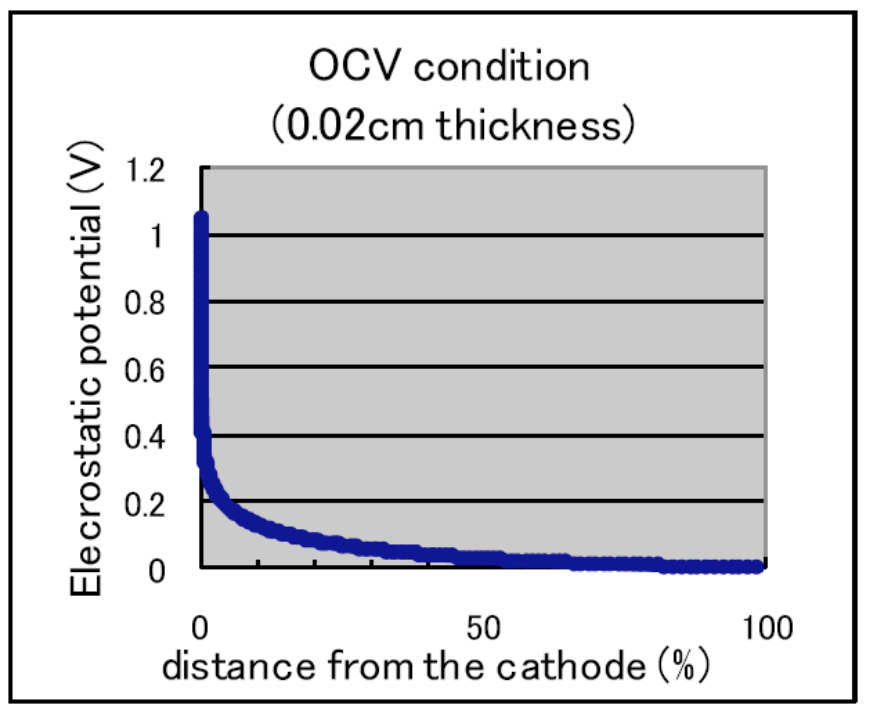

Fig. (12). Relationship between the distance from the cathode and the electrostatic potential.

A large voltage drop was observed in $0.02 \%$ of the thickness of the electrolyte near the cathode.

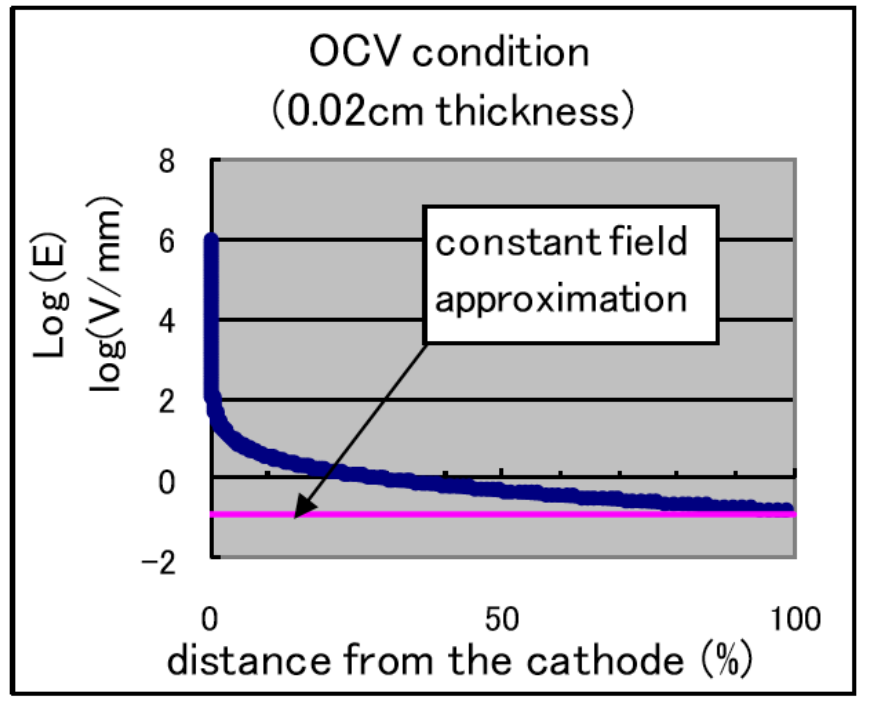

Fig. (13). Relationship between the distance from the cathode and $\log (\mathrm{E})$

\subsection{Electrical Field Considering Polarization Voltage Losses}

The calculated relationship between the distance from the cathode and $\log (\mathrm{E})$ under OCV conditions is shown in Fig. (14). Even when polarization voltage losses were considered, E near the cathode was greater than $300 \mathrm{kV} / \mathrm{mm}$, sufficiently large to cause a dielectric breakdown. 
But these results are only examples. From Equation 28, fmesh(r) is;

$$
f_{\text {mesh }}(r)=\frac{E \times L}{E \times L+\left(1-f_{\text {average }}(r)\right) \times V_{\text {th }}}
$$

here, faverage(r) should be smaller than the values without polarization voltage losses. So the smallest fmesh(r) is 0.99997 with E, faverage(r), L and Vth at $20 \mathrm{kV} / \mathrm{mm}, 0.898$, $0.02 \mathrm{~cm}$ and $1.174 \mathrm{~V}$, respectively. So, the largest $p O_{2_{2} m e s h}$ is $2.46 \times 10^{-7} \mathrm{~atm}$. Then, cathode polarization voltage loss to avoid large electric field should be;

$V_{c}=\frac{R T}{4 F} \ln \left(\frac{1}{2.46 \times 10^{-7}}\right) \geq 0.287 \mathrm{~V}$

This value is too large. So it is impossible to avoid large electric field in the electrolyte. Presently, very thin electrolytes (e.g., $0.01 \mathrm{~mm}$ ) can be constructed. In this case, the $\mathrm{E}$ becomes 20 times larger in value. Consequently, theoretical limitations cannot be solved, even when polarization voltage losses are taken into account.

\section{OCV condition considering} polarization voltage losses $0.02 \mathrm{~cm}$ thickness

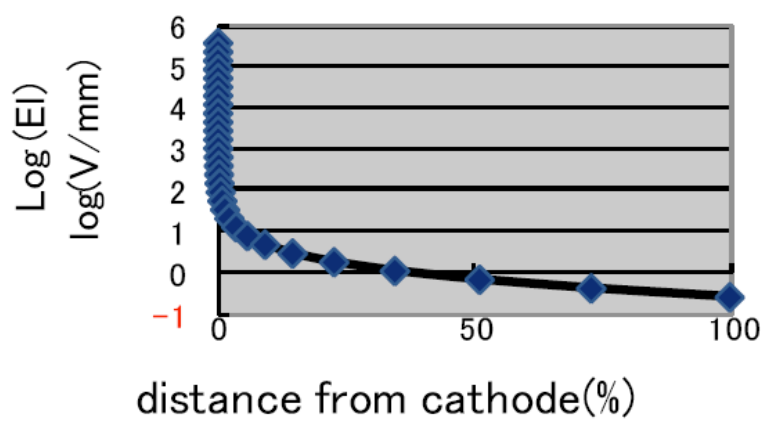

Fig. (14). Relationship between the distance from the cathode and $\log (\mathrm{E})$ considering polarization voltage losses.

\section{CONCLUSIONS}

In this report, a new calculation method that considers the electric field is expressed only from Wagner's equation to solve the current-voltage problem in MIECs. The calculated results match values from conventional models. We found that the constant field approximation (linear assumption) is not an approximation but a direct deduction from Wagner's equation.

However, the definition of $\mathrm{E}$ should be changed when there is a large voltage drop in the thin area of the electrolyte when compared with the lattice constant. The electric field near the cathode was sufficiently to cause a dielectric breakdown, which has never been reported. Consequently, there are limitations to Wagner's equation, which come from the limits of linear transport theory. These limitations cannot be solved even considering polarization voltage losses.
The experimental verification of leakage currents using SDC electrolytes has already been noted, both qualitatively and quantitatively. Two types of conclusions exist when the experimental results are different from the theoretical results:

Case 1: The theory is perfect; however, there are technological problems.

Case 2: There is a voltage loss that cannot be explained by any available theories.

If there is confusion between Case 1 and Case 2, problems will arise in the use of MIECs, not only in SOFCs but also in every other area of solid state ionics. Leakage currents in SOFCs using doped ceria electrolytes must be fully verified theoretically.

\section{ACKNOWLEDGEMENT}

This report is based on my previous report [13]. The differences are:

a. Choudhury-Paterson style is used.

b. Polarization voltage losses are considered.

c. The definition of electric field is explained more detail.

d. From the conventional definition of electric field, the constant field approximation is not assumption, but the direct deduction of Wagner's equation.

e. The calculation procedure is explained in detail.

\section{APPENDIX 1}

A mathematical proof for equation 17 is given here.

\section{Symbol List}

\begin{tabular}{|l|l|l|}
\hline \multicolumn{1}{|c|}{ Symbol } & \multicolumn{1}{c|}{ Explanation } & Status \\
\hline \hline $\mathrm{r}$ & $\begin{array}{l}\text { ratio of the ionic to the electronic } \\
\text { current }\end{array}$ & cell variable \\
\hline $\mathrm{N}$ & mesh number & constant \\
\hline$p O_{2}^{\prime}$ & oxygen partial pressure at the cathode & constant \\
\hline$p O_{2}^{\prime \prime}$ & oxygen partial pressure at the anode & constant \\
\hline $\mathrm{Vth}$ & Nernst voltage of the cell & determined \\
\hline $\mathrm{Vcell}$ & cell voltage & cell variable \\
\hline $\mathrm{Vth} \_m e s h$ & Nernst voltage of the mesh & determined \\
\hline Vmesh & voltage across each mesh & mesh variable \\
\hline faverage(r) & Vcell / Vth & cell variable \\
\hline fmesh(r) & Vmesh/Vth_mesh & mesh variable \\
\hline $\mathrm{L}$ & thickness of the electrolyte & constant \\
\hline Lmesh & thickness of the mesh & mesh variable \\
\hline Laverage & $\begin{array}{l}\text { thickness of the mesh when fmesh(k) } \\
\text { is equal to faverage(k) }\end{array}$ & determined \\
\hline Ri & ionic resistance of the electrolyte & constant \\
\hline Rion & ionic resistance of the mesh & mesh variable \\
\hline
\end{tabular}


$V_{\text {cell }}=f_{\text {average }}(r) \times V_{\text {th }}$

The difference in $\ln \left(\mathrm{pO}_{2}\right)$ between the cathode and anode sides of the mesh is $\frac{\ln \left(p O_{2}^{\prime}\right)-\ln \left(p O_{2}^{\prime \prime}\right)}{N}$.

$l_{\text {average }}=\frac{L}{N}$

$V_{t h \_m e s h}=\frac{V_{t h}}{N}$

$V_{\text {cell }}=\sum_{1}^{N} V_{\text {mesh }}=\sum_{1}^{N}\left(f_{\text {mesh }}(r) \times V_{\text {th_mesh }}\right)=\frac{V_{\text {th }}}{N} \sum_{1}^{N} f_{\text {mesh }}(r)$

Thus, from Equations a1 and a4,

$\frac{1}{N} \sum_{1}^{N} f_{\text {mesh }}(r)=f_{\text {average }}(r)$

From Equation 15,

$\sum_{1}^{N} l_{\text {mesh }}=\sum_{1}^{N} l_{\text {average }}\left(\frac{1-f_{\text {mesh }}(r)}{1-f_{\text {average }}(r)}\right)=\frac{N \times l_{\text {average }}}{1-f_{\text {average }}(r)} \times \frac{1}{N} \sum_{1}^{N}\left(1-f_{\text {mesh }}(r)\right)$

Therefore, from Equations a5 and a6,

$\sum_{1}^{N} l_{\text {mesh }}=\frac{L}{1-f_{\text {average }}(r)}\left(1-f_{\text {average }}(r)\right)=L$

Consequently, when Equation a7 is satisfied, the cell voltage and electrolyte thickness become the actual values. Next, from Equations 6, 9 and a1,

$I_{e}=\frac{I_{i}}{r}=\frac{\left(V_{\text {cell }}-V_{\text {th }}\right)}{r \times R_{i}}=\frac{\left(f_{\text {average }}(r)-1\right)}{r} \times \frac{V_{\text {th }}}{R_{i}}$

For each mesh,

$I_{e}=\frac{\left(f_{m e s h}(r)-1\right)}{r} \times \frac{V_{t h}}{N} \times \frac{1}{r_{\text {ion }}}$

Here, the ionic conductivity is constant. Thus,

$\frac{r_{\text {ion }}}{l_{\text {mesh }}}=\frac{R_{i}}{N \times l_{\text {average }}}$

From Equation a10,

$\frac{1}{N \times r_{\text {ion }}}=\frac{l_{\text {average }}}{R_{i} \times l_{\text {mesh }}}$

From Equations a9 and a11,

$$
I_{e}=\frac{\left(f_{\text {mesh }}(r)-1\right)}{r} \times \frac{l_{\text {average }} \times V_{\text {th }}}{l_{\text {mesh }} \times R_{i}}
$$

Considering continuity, from Equations a9 and a12,

$l_{\text {mesh }}=l_{\text {average }}\left(\frac{1-f_{\text {mesh }}(r)}{1-f_{\text {average }}(r)}\right)$

Equation a13 is equal to Equation 17. Consequently, the cell voltage, thickness and continuity are reflected in Equation 17. Thus, Equation 17 is satisfied with the generalized version of Wagner's equation using the Choudhury and Patterson style.

\section{APPENDIX 2}

The comparison with data between in this report and the previous report [13] are explained in this Appendix 2.

The value of $\mathrm{E}(=\mathrm{V}$ cell $/ \mathrm{L})$ to calculate the constant field in [13] became larger than shown in Equation 25. But any other results in this report are compatible with those in [13], since Equation 17 in this report is same with Equation 18 in [13], even though Equation 6 in this report is different from Equation 10 in [13].

\section{REFERENCES}

[1] Wagner C. Beitrag zur Theorie des Anlaufvorgangs. Z Phys Chem 1933; B41: 42.

[2] Rickert H. Electrochemistry of solids - an introduction. Berlin Heidelberg: Springer 1982; p. 99.

[3] Zha SW, Xia CR, Meng GY. Calculation of the e.m.f. of solid oxide fuel cells. J Appl Electrochem 2001; 31: 93-8.

[4] Riess I. Current-voltage relation and charge distribution in mixed ionic electronic solid conductors. J Phys Chem Solids 1986; 47: 129-38.

[5] Miyashita T. Necessity of verification of leakage currents using Sm doped Ceria electrolytes in SOFCs. J Mater Sci 2006; 41: 3183-4.

[6] Lai W, Haile SM. Electrochemical impedance spectroscopy of mixed conductors under a chemical potential gradient: A case study of Pt|SDC|BSCF. Phys Chem Chem Phys 2008; 10: 865-83.

[7] Riess I. Review of the limitation of the Hebb-Wagner polarization method for measuring partial conductivities in mixed ionic electronic conductors. Solid State Ionics 1996; 91: 221-32.

[8] Guo W, Liu J, Zhang Y. Electrical and stability performance of anode-supported solid oxide fuel cell with strontium- and magnesium-doped lanthanum gallate thin electrolyte. Electrochim Acta 2008; 53: 4420-7.

[9] Lima Hyung-Tae, Virkar Anil V. Measurement of oxygen chemical potential in thin electrolyte film, anode-supported solid oxide fue cells. J Power Sources 2008; 180: 92-102.

[10] Choudhury NS, Patterson JW. Performance Characteristics of Solid Electrolytes under Steady-State Conditions. J Electrochem Soc 1971; 118: 1398-403.

[11] Singh R, Jacob KT. Calculation of the oxygen potential profile across solid-state electrochemical cells. J Appl Electrochem 2003; 33: 571-6.

[12] Riess I. Theoretical treatment of the transport equations for electrons and ions in a mixed conductor. J Electrochem Soc 1981; 128: 2077-81.

[13] Miyashita T. Theoretical verification necessity of leakage currents using Sm doped Ceria electrolytes in SOFCs. Open Mater Sci J 2009; 3: 33-9. 